\title{
Konsep dan Makna Kesejahteraan dalam Pandangan Islam
}

\author{
Muhammad Arsyam, S.Pd.I., M.Pd. \\ Email: arsyam0505@gmail.com \\ Andi Mujaddidah Alwi, S.Pd., M.Pd. \\ Email: dhidapijarjingga@gmail.com \\ Sekolah Tinggi Agama Islam Darud Dakwah wal Irsyad (STAI DDI) Kota Makassar
}

Oleh:

\begin{abstract}
Abstrak
Dalam ajaran Islam, konsep dan makna kesejahteraan menjadi salah satu hal yang terpenting dalam kehidupan. Salah satu tolok ukur kesejahteraan adalah faktor ekonomi. Kesejahteraan sosial bukan hanya hubungan terhadap transendental akan tetapi juga harus dibarengi dengan hubungan horizontal kepada sesama manusia. Mewujudkan kesejahteraan merupakan sosial, merupakan misi kekhalifahan yang dilakukan oleh para Nabi dan Rasul Allah.
\end{abstract}

Kata Kunci: Ekonomi, Kesejahteraan, Pandangan Islam.

\section{Pendahuluan}

Terdapat sejumlah argumentasi baik yang bersifat teologis n0rmatif, maupun rasional filosofis yang menegaskan tentang betapa ajaran Islam amat peduli dalam mewujudkan kesejahteraan sosial.

\section{Pembahasan}

Pertama dilihat dari pengertiannya, sejahtera sebagai mana dikemukakan dalam Kamus Besar Indonesia adalah aman, sentosa, damai, makmur dan selamat (terlepas) dari segala macam gangguan, kesukaran dan sebagainya (Fadilah, 2020). Pengertian ini sejalam dengan pengertian Islam yang berarti selamat, sentosa, aman dan damai (Wahidah, 2018). Dari pengertiannya ini dapat diketahui bahwa masalah kesejahteraan sosial sejalan dengan missi Islam itu sendiri. Misi inilah yang sekaligus menjadi misi kerasulan Nabi Muhammad SAW, sebagaimana dinyatakan dalam ayat yang berbunyi :

Artinya: Dan tidalah kamu mengutus kamu, melainkan untuk (menjadi) rahmat bagi seluruh alam. (Q.S. al-anbiya' 21:107)

Kedua dilihat dari segi kandungannya, terlihat bahwa seluruh aspek ajaran Islam ternyata selalu terkait dengan masalah kesejahteraan sosial (Kholis, 2015). Hubungan dengan Allah misalnya harus dibarengi dengan hubungan dengan sesama manusia (habl min Allah wa habl min al-Nas). Demikian pula anjuran beriman selalu diiringi dengan ajuran melakukan amal salih yang didalamnya termasuk mewujudkan kesejahteraan sosial. Selanjutnya ajaran Islam yang pokok yakni Tukun Islam, seperti mengucapkan dua kalimah syahadat, shalat, puasa, zakat dan haji sangat berkaitan dengan kesejahteraan sosial (Tahkim, 2016). Orang yang mengucapkan dua kalimah syahadat adalah orang yang komitmen bahwa hidupnya hanya akan berpengan pada pentunjuk Allah dan Rasul-Nya, karena tidak mungkin orang mau menciptakan ketenangan, jika tidak ada komitmen iman dalam hati nya. Demikian pula ibadah shalat (khususnya yang dilakukan secara berjama'ah) mengandung maksud agar mau memperhatikan nasib orang lain (Suparman, 2015). Ucapan salam pada urutan terakhir dalam tarnyam dan berupaya mewujudkan kedamaian. Selanjutnya dalam ibadah puasa seseorang diharapakan dapat merasakan lapar sebagaimana yang biasa dirasakan oleh orang lain yang berada dalam kekurangan (Mufaizin, 2018). Demikian pula dengan ibadah haji dan umrah, diharapkan agar ia memiliki sikap merasa sederajat dengan manusia lainnya (Hajar, 2014). Kemudian dalam zakat, tampak jelas unsur kesejahteraan sosialnya lebih kuat lagi.

Ketiga, bahwa upaya mewujudkan kesejahteraan sosial, merupakan missi kekhalifahan yang dilakukan oleh Nabi Adam AS (Hafid, 2019). sebagian pakar, sebagaimana dikemukakan H.M. Quraish Shihab dalambukunya Wawasan Al-Quran (hal. 127), menyatakan bahwa kesejahteraan sosial yang didambakan al-Quran 
tercermin di Surga yang dihuni oleh Adam dan istirinya, sesaat sebelum turunnya mereka melaksanakan tugas kekhalifahan di bumi. Seperti diketahuin, bahwa sebelum Adam dan istirinya diperintahkan turun kebumi, mereka terlebih dahulu ditempatkan di surga. Surga diharapkan menjadi arah pengabdian Adam dan Hawa, sehingga bayang-bayang surga itu diwujudkan di bumi, serta kelak dihuninya secara hakiki di akhirat. Masyarakat yang mewujudkan bayang-bayang surga itu adalah masyarakat yang berkesejahteraan (Almahmudi, 2019). Kesejateraan surgawi ini dilukiskan antara lain dalam firman-Nya yang berbunyi :

Artinya: hai adam sesungguhnya ini (iblis ) adalah musuh bagimu dan bagi istirimu, maka sekali-kali jangan sampai ia mengeluarkan kamu berdua dari surga, yang akibatnya engkau akan bersusah payah. Sesungguhnya engkau tidak akan kelaparan di sini (surga), tidak pula akan telanjang, dan sesungguhnya engkau tidak akan merasakan dahaga maupun kepanasan. (Q.S. Thaha, 20:117-119).

Dari ayat ini jelas bahwa pangan, sandang, dan papan yang diistilahkan dengan tidak lapar, dahaga telanjang dan kepanasan semuanya telah terpenuhi di sana. Terpenuhinya kebutuhan ini merupakan unsur pertama dan utama kesejahteraan sosial.

Keempat, di dalam ajaran Islam terdapat pranat dan lembaga yang secara langsung berhubungan dengan upaya penciptaan kesejahteraan sosial, seperti wakaf dan sebagainya. Semua bentuk pranata sosial dan berupaya mencari berbagai alternatuf untuk mewujudkan kesejahternaan sosial. Namun suatu hal yang pelu dicatat, adalah bahwa berbagai bentuk pranat ini belum merata dilakukan oleh umat Islam, dan belum pula efektif dalam mewujudkan kesejahteraan sosial. kebutuhan air bersih meniadi sangat penting, dan meniadi tolok ukur keseiahteraan, (Arsyam, M., Nurfatimah, N., Sainuddin, I. H., S, Jusmiana, A., \& Alam, S. (2020, July). Hal ini mungkin disebabkan belum munculnya kesadaran yang merata serta pengelolaannya yang baik. Untuk itulah saat ini pemerintah, melalui Departemen Agama, membentuk semacam Lembaga Amil Zakat (LAZ) tingkat Nasional. Berhasilkan konsep ini dalam mewujudkan kesejahteraan sosial, amat bergantung kepada partisipasi kita.

Kelima, ajaran Islam mengenai perlunya mewujudkan kesehateraan sosial ini selain dengan cara memberikan motivasi sebagaimana tersebut di atas, juga disertai dengan petunjuk bagaimana seharusnya mewujudkannya. Di era sosial media seperti sekarang ini dakwah menjadi salah satu kebutuhan kesejahteraan (Sainuddin, 2020). Ajaran Islam menyatakan bahwa kesehateraan sosial dimulai dari perjuangan mewujudkan dan menumbuh suburkan aspek-aspek akidah dan etika pada diri pribadi, karena dari diri pribadi yang seimbang akan lahir masyarakat yang seimbang. Dalam Pendidikan juga mempengaruhi kemampuan kesejahteraan sosial (Arsyam, 2020). Masyarakat Islam pertama lahir dari Nabi Muhammad SAW, melalui kepribadian beliau yang sangat mengagumkan. Pribadi ini melahirkan keluarga yang seimbang seperti Khadijah, Ali bin Abi Thalib, Fatimah Az-Zahra, dan lain-lain. Selain itu ajaran Islam menganjurkan agar tidak memanjakan orang lain, atau kreatifitas orang lain, sehingga orang tersebut tidak dapat menolong dirinya sendiri. Aktivitas dakwah mampu mempengaruhi dalam konsep kehidupan dan makna kesejahteraan (Sainuddin, 2020). Bantuan keuangan baru boleh diberikan apabila seseorang ternyata tidak dapat memenuhi kebutuhannya (Imran, 2003). Ketika seseorang datang kepada Nabi SAW. mengadukan kemiskinannya, Nabi SAW tidak memberinya uang, tetapi kapak agar digunakan untuk mengambil dan mengumpulkan kayu. Dengan demikian, ajaran Islam tentang kesejahteraan sosial ini termasuk di dalamnya ajaran Islam tentang kesejahteraan sosial.

\section{Kesimpulan}

Konsep dan makna kesejahteraan menjadi salah satu hal yang terpenting dalam kehidupan. Salah satu tolok ukur kesejahteraan adalah faktor ekonomi. Kesejahteraan sosial bukan hanya hubungan terhadap transendental akan tetapi juga harus dibarengi dengan hubungan horizontal kepada sesama manusia. 


\section{Daftar Pustaka}

Almahmudi, N. M. T. (2019). Konsep Kesejahteraan dan Implementasinya dalam Perspektif Hukum Islam. Khuluqiyya, 1(2), 1-19.

Arsyam, M. (2020, August 3). PENGARUH KEMAMPUAN SUPERVISIONAL KEPALA SEKOLAH DAN PERAN KOMITE SEKOLAH TERHADAP KINERJA GURU SMA NEGERI DI KOTA MAKASSAR. https://doi.org/10.31219/osf.io/j84ew

Arsyam, M., Nurfatimah, N., Sainuddin, I. H., S, Jusmiana, A., \& Alam, S. (2020, July 8). Changes in Community Attitudes and Their Participation in the Community-Based Water Supply and Sanitation Program (PAMSIMAS) in Gowa Regency. https://doi.org/10.31219/osf.io/gk569

Fadilah, N. (2020). Konsep Kesejahteraan Sosial dalam Perspektif Ekonomi Islam. Salimiya: Jurnal Studi Ilmu Keagamaan Islam, 1(1), 49-67.

Hafid, H. (2019). Money Politic di Tengah Dilema Kesejahteraan Masyarakat. Jurnal Kariman, 7(1), 97-108.

Hajar S, I. (2014). Sistem Pengelolaan Bimbingan Manasik Haji-Umrah pada PT. AlBayan Permata Ujas (Doctoral dissertation, Universitas Islam Negeri Alauddin Makassar).

Imron, M. (2003). Kemiskinan dalam masyarakat nelayan. Jurnal Masyarakat dan Budaya, 5(1), 63-82.

Kholis, N. (2015). Kesejahteraan Sosial Di Indonesia Perspektif Ekonomi Islam. AKADEMIKA: Jurnal Pemikiran Islam, 20(2), 243-260.

Mufaizin, M. (2018). Kearifan Syariat dan Hikmah dalam Puasa. Al-Insyiroh: Jurnal Studi Keislaman, 2(1), 103-127.

Sainuddin, I. H., S. (2020, August 7). Aktivitas Dakwah di Masa New Normal. https://doi.org/10.31219/osf.io/dejy2

Sainuddin, I. H., S. (2020, July 27). Dakwah di Era Sosial Media. https://doi.org/10.31219/osf.io/2jxny

Suparman, D. (2015). Pembelajaran ibadah shalat dalam perpektif psikis dan medis. JURNAL ISTEK, 9(2).

Takhim, M. (2016). Sistem Ekonomi Islam Dan Kesejahteraan Masyarakat. AlMabsut: Jurnal Studi Islam dan Sosial, 10(2), 436-451.

Wahidah, S. B. (2018). DIMENSI EKONOMI DALAM KEHIDUPAN NABI ADAM (TAFSIR SURAT THAHA AYAT 117-119 dan SURAT ALBAQARAH AYAT 36). EKSISBANK: Ekonomi Syariah dan Bisnis Perbankan, 2(2), 31-35. 